\title{
Theoretical Bases and Methodical Matters of Innovation-Active Organizations Cooperation Management Under the Condition of Uneven Technological Development
}

\author{
Elza Alekseeva \\ Institute of Economics, Finance and Business \\ Federal State Budgetary Educational Institution of Higher \\ Education «Bashkir State University» \\ Ufa, Russia \\ elza.kinzyagulova@list.ru
}

\author{
Dmitrii Kotov \\ Institute of Oil and Gas Business \\ Federal State Budgetary Educational Institution of Higher \\ Education «Ufa State Petroleum Technological University» \\ Ufa, Russia \\ koroltay@mail.ru
}

\begin{abstract}
The article gives the results of the research of cooperation management in the innovative environment. The necessity of introducing to scientific use the term "technological field" that defines logic and mechanics of innovative activity concentration in the most supportive environment (innovative environment), which lets the companies attain maximal economical goods (benefits) from innovation development, is determined. The model of innovative environment operation in the context of technological development level is presented. Also, the rationale and corresponding mathematical model are presented that describe key directions of managing actions for accelerating the innovative environment growth. Management suggestions for cooperation management to stimulate technological development are formalized.
\end{abstract}

Keywords: cooperation management, innovative environment, technological field, regional technological development

\section{INTRODUCTION}

The processes of economic and technological development in the context of global competition prompt to find and purposefully strengthen those factors that would be best suited to specifics and potential of the target asset. From the view of region or country management in the context of worldwide labor differentiation and economical specifics of national economies, the most important is to find a particular pool of manageable factors. This pool of factors should allow maintaining the current stability of the existing collaboration system of companies and organizations with the partners but at the same time let to strengthen the scientific and technological position of country or region in the new technological wave coming into being. The theories of technological waves allow us to suggest at that time, which groups of technologies, and which corresponding business we should support. Theories of economic growth permit regulating taxation and administrative workload of innovators. Understanding the importance of economic stimulation of innovations lets us define the term "innovative environment", to develop and mostly successfully implement the approach of effort concentration for the creation and employment of technological innovations in various regions. Thereby, technopolises, technological parks and various cluster structures were created and are working all over the world. It should be noted that the success of their activity is differentiating exceptionally.

However, the process of technological development intrinsically is uneven. Technological rent income is formed and allocated in established traditional forms of interaction in countries-leaders. This is an obvious pattern that duplication in efforts of the creation of innovative environment supportive structures in other countries does not let to smooth the conditions for technological creativity and implementation of innovations for enterprises. One could overcome technological inequality in the process of new technological wave establishment with the help of new mechanisms that are adjusted by application methods and particular properties for a territory where the innovative environment is created. Therefore, such a factor, the influence of which has not been studied thoroughly for some reason, should be chosen for the research of the innovative environment development of a particular region or country. Otherwise, it could be a factor the ways of stimulating the influence of which on innovative creativity were not considered as a priority.

In the set context, we have focused on cooperation as a phenomenon the successful management of which on the level 
transnational companies for the strengthening of their competitiveness.

The works of N.V. Yakovets, R. Kamani, L.I. Abalkina, S.Yu. Glazyev, L.M. Gokhberg, L.E. Mindeli, E. Andreeva, P. Zavlin, S. Ivanchenko, S.D. Ilyenkova, M. Castells, S. Kuznetsova, X. Neubauer, V. Soloviev are dedicated to the creation and development of an innovative environment in modern economics. Integration and cooperation, and the level of technological development are considered as necessary components or resultant from the level of innovative environment development.

All the mentioned spheres of scientific researches, theoretical and practical results obtained have created the unique possibility for a complete rethink of the role of cooperation in the innovative environment. This has demanded the research of the connection between technological development and cooperative relationships in an innovative environment, the development of theory and the creation of tools for the practical use of new knowledge.

\section{RESEARCH METHODS}

The wide range of methodologies was used for the contemplation of accumulated knowledge, empiric materials, setting up and solving the objectives. The following should be noted as the basis of scientific methods of cognition used: (1) retrospective analysis and synthesis methods were used to assess the levels and rates of economic and technological development at the mesoscale; (2) the method of system analysis allowed us building the dependence of the growth rate of the spread of technology and technological and economic development on the level of cooperation; (3) the classification method gave ground for systematizing the results of assessing the level of development of cooperation among subjects of the innovation environment, taking into account the results of the analysis of statistical data, (4) statistical analysis methods; (5) expert methods; (6) normative and scenario forecasting; (7) formal logic tools were used to develop hypotheses, test them, assess the convergence of theoretical conclusions and the actual results of regional development.

Thus, we can see the practical necessity for new scientific results and the objective possibility of attaining them. First of all, there is a necessity for development, theoretical explanation, and practical use of mesoscale technological development management tools. These tools will help to reduce the gap in technological and economical level between countries and regions. Secondly, a vast base of theoretical knowledge and experience in the field off technological development and cooperation has been accumulated. And, thirdly, we have chosen the necessary and sufficient pool of methods for research and design.

\section{A. Hypothesis}

Effective management of technological development in modern conditions can be ensured through the management of cooperation between companies in an innovative environment. This is because of a relationship between the comparative speed of technological and economic development, and the
Petrishcheva, Yu.V. Piskulova, Yu.Yu. Possysaeva, Yu.A Savinova, M.Yu. Hlynina, S.G. Khomich. Cooperation is considered as an instrument of the collaboration of 
level of cooperation in the innovation environment in the conditions of uneven regional technological development.

Moreover, the unevenness of regional technological development should be considered in the context of theories of technological waves, taking into account the increasingly complex and diverse influence of various factors on the development of technologies.

\section{THE RESULTS OF THE RESEARCH}

\section{A. The logic of concentration innovative activity of the enterprises in the innovative environment}

Cyclic changes of the world economy are based among others on the dynamic process of design and engineering improvements that are inevitable due to scientific and technological progress and transition from the lowest to the highest technological waves. At the same time, the fundamental basis of technological wave's theories does not pay enough attention to objectively existing unevenness of development, the sources that cause it, and the consequences of this unevenness [1-5]. Technological development at mesoscale depends on various factors that allow complementing the classical view on the technological waves' change.

The influence of availability of resources, restriction of the use of technologies due to various reasons, immatureness of the market and society because of an absence of demand for innovations, and difficult political situation of territory (region/country) are still not recognized in the classical theory of technological waves. Due to this, the level of technological development is usually characterized by the point of its length, it's a current phase, and its basic technology (fig. 1)

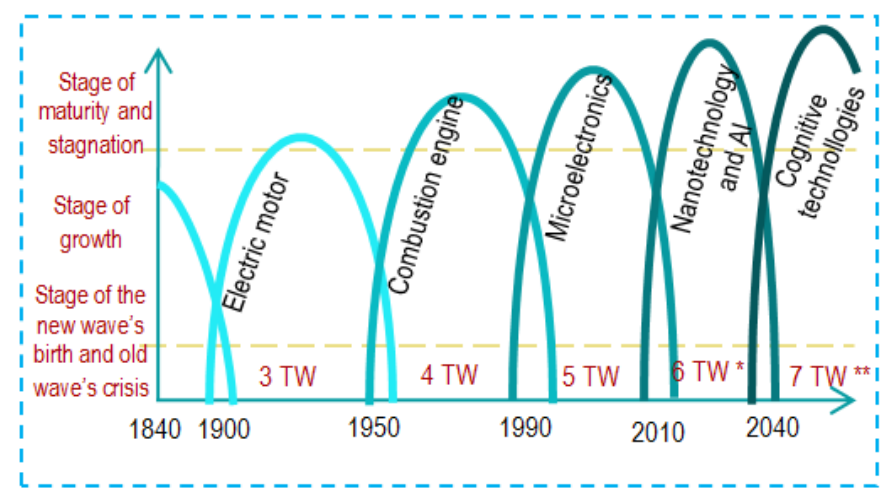

Fig. 1. The classical model of technological wave (according to the works of J. Schumpeter, * D.S. Lviv and S.Yu. Glazyev, ** V.E. Lepsky and I.A. Prokhorova)

A fundamental look at the change of technological wave lets us measure and forecast processes of long-termed economic and technological progress on the future based on retrospective analysis and established patterns [6]. However, this view of technological waves is not enough for management purposes [7]. The rationale of technological development in the context of innovative activity concentration in the fields (innovative environments) that allow enterprises to maximize the economic benefits from innovation development should become an important addition.

Within this framework, we suggest improving the model of technological wave and adding to it gradation of levels of technological development within one particular technological wave by implementing the term "technological field". The technological field is a sphere of technological development within the dominating technological wave that includes alternative technologies emerging, developing with the particular speed that results from the existing influence of external factors, and competing among themselves. The technological field determines the level and unevenness of regional technological development in the scope of one particular technological wave and is connected to technological fields of other basis technologies (fig. 2). The group of basis technologies forms an aggregate of noncompeting technologies from different spheres of technological development of one technological wave.

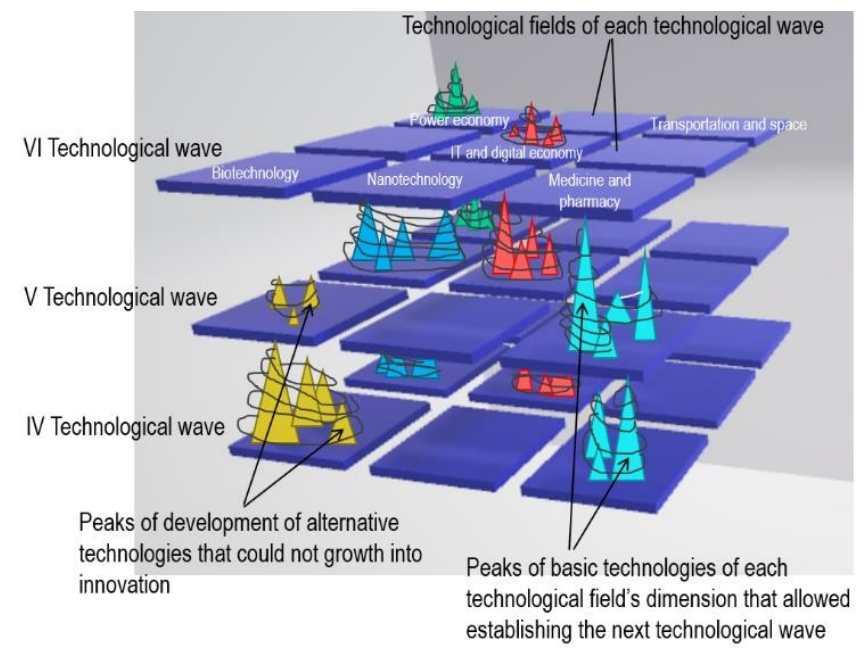

Fig. 2. A general idea of the technological fields

Technological fields in a static state are not informative, therefore, it is important to reflect the dynamics of processes through indicators of speed and quality of development.

Let's consider the fig.2. Disturbance or turbulence of technological field is an objectively observed phenomenon of development of at least one alternative (competing) technologies that lie within one technological field and transition of one of the technologies to a dominant position as a result of such phenomenon. Turbulences of technological field can be determined by amount of disturbances (alternative technologies), the pace of progress in research and implementation of finished goods (or services) in the market for each alternative, relative coverage area of one technology in relation to others (the percent of innovative process participants that start to use this technology).

The pace of progress in the implementation of technologies (innovations) in the face of competition or the struggle to spread one of the alternative technologies should be reflected in the form of peaks in the technological field. The growth of the peak before stepping into the next level determines the process of the next technological wave 
formation. After this, according to the concept of the life cycle, the technology goes to the maturity stage, where the need for it decreases, and the innovation goes to the crisis stage. Following the obsolescence of this innovation, there is a need for a new core technology, which will also form the next way, and again on a competitive basis.

A modified model of change of the technological wave allows defining the logic of enterprises' innovative activity concentration in correspondence with technological development. This logic is based on the following suggestions. The growth of demand for innovations happens in the downward stage of technological wave or the declining and crisis phase [8]. This happens because at this stage the development and implementation of radical innovations forming the core of the next technological wave happen under the pressure of rapid decrease of revenue and obsolescent technologies. The beginning of innovation expansion testifies the start of a new cycle and its replacement of precede crisis.

The suggestion that new technology appears for a defined inquiry as an answer to existing issues implies that there are unsuccessful attempts of finding the solution. Stemming from the influence of a vast range of factors and conditions, only some of the new technologies solve the issue with a maximum effect. This leads to the possibility for them to grow into innovation, thus meaning they will be implemented and commercialized. The appearance of innovations is connected to the maximal concentration of activities (efforts) on solving the issue in a particular sphere called an innovative environment. The number of companies that acknowledge this technology as the basis also is connected to the appearance of innovations. Exactly such phenomenon reflects the value of technological field disturbance area - the bigger it is, the bigger are efforts' concentration on research and development, and the faster one of the alternative technologies will become dominant or basic.

The projection of the phenomenon of the technological field reflects the competition between alternative technologies in a bid for the right to become basis technology of the new technological wave (fig. 3).

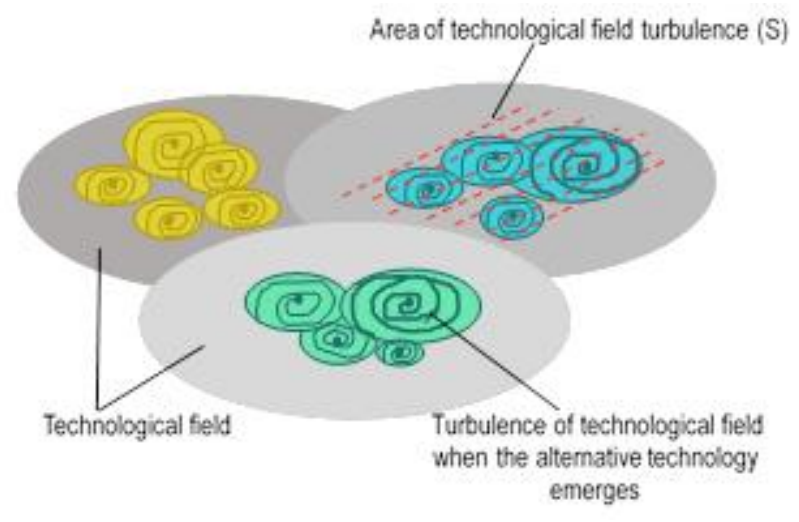

Fig. 3. The concentration of innovative activity of companies around alternative growth points in the technological field (general outline)
The turbulence of the technological field in this projection is equivalent to the schematic representation of the peaks of the basic technology in the previous fig. 2.

The pace of progress or the speed of innovation growth equals the period for the new technology to grow from the inception to the stage of maturity. The internal "quality" of the company that initiates the innovation, the level of technological, economic, financial, personnel, organizational, and management development and the innovative environment influence where the company is located define the speed of innovation growth. Because the study of the company's management is not the purpose of this study, the assumption is made that it is equally effective and only the external influence or the environment in which the company develops is considered.

As a result, any of the technological fields at that any point of time could be presented as a pool of peaks and the disturbance around them. The necessity for choosing alternative solutions to maintain their position at the market in the future appears for every company. The concentration of companies around this or that innovation became actual specifically from the point of technological leadership of innovators. The facilitation of this concentration is the main purpose of the management of innovative development at the mesoscale.

\section{B. Managed factors to stimulate technological development}

The innovative environment (IE) where the origin of innovation happens (it is preferable the innovation to be the most competitive at the whole technological field) is designed for the provision of conditions favoring the generation of new scientific knowledge and its transfer to applied spheres of society. There is a known notice that subjects in the mature environment who are actively participating in innovative processes are striving to collaborate so that they can establish mutually beneficial relations, dissipation of high risks of $\mathrm{R} \& \mathrm{D}$, and effective resource distribution [9].

In this regard, we propose to add collaboration stimulation measures - cooperation, in the definition of the innovation environment. Therefore, the innovation environment should be understood as a set of phenomena, processes, external and internal conditions that affect the implementation of innovative activities of subjects, as well as the system of interconnected relationships of subjects. Thereby innovation environment allows obtaining a result that ensures a qualitative increase in the efficiency of processes or production of products demanded by the market [10]. A feature of the innovative environment is the generation of synergy obtained from the interaction of its constituent subjects, while the added value is obtained not from the cumulative effect of the subjects, but their interaction. Manufacturers of solutions as a result of the intellectual process are the subjects of the innovation environment. Those include research institutes, universities, lone innovators (science), manufacturers of the final product or service (business), consumers of the innovation process (market), elements of the innovation infrastructure, including investors 
technological development at the same level, understanding of current and future trends);

- availability of innovative infrastructure and communication channels;

- implementation of innovative activities by subjects with the achievement of a synergistic effect.

An analysis of factors contributing to the formation of an innovative environment and scientific design allows us to move on to a model of the functioning of an innovative environment in conjunction with the level of technological development. From technological development, the economy is being transformed not only due to the introduction of new technologies but also due to a change in the form of relations between the subjects of the innovation environment, communication channels and ways of interaction.

For example, from the beginning of the mass use of the Internet, completely new forms of communication that are actively used by companies to interact with the external environment have appeared and continue to develop. New communication channels that have arisen under the influence of globalization permit companies from different parts of the world to cooperate and interact with each other, integrating their advantages to create new products. The concept of open innovation is attracting more and more companies to the partnership to search for meaningful and innovative solutions to meet customer needs and maximize the commercial value of investments [8,13,14].

This is confirmed by examples of cooperation between companies and the development of joint innovative projects for the creation of new products and services [15].

Of course, the technologies of the third and fourth technological waves did not have the ability to form such forms of relationships and provide high-speed communication channels. This happened with the advent of the fifth technological wave and the spread of information technology, the development of software and telecommunications [1]. A change in the ways and forms of interaction of the subjects of the innovative environment, depending on the change in technological patterns, is reflected in the innovation environment itself, it is also being modified.

The rejection of the mandatory regional-territorial binding of the technological field or the innovation environment is important today.

For example, if we consider the innovative environment of the 3rd and 4th waves, there is a connection with the development of the territory of the company's presence [16]. The innovative environment of the 5th and 6th waves is fundamentally different because of its network form and the lack of territorial affiliation of companies. In connection with the implementation of dynamic activities in the global space, companies communicate and build relationships around the world, which affects the level and pace of development of their innovative environment [15, 17-19].

Therefore, it remains to take the role and strength of the cooperative relationships of companies as a basic 
environment, such as economic, political, social, financial and other factors, is not excluded [20,21].

The level of technological development, initial or reached to the current moment, determines in many respects the position of a leader or a catching up in technological development. However, economic incentives, affordable loans, and other financial support measures help attract companies to this innovative environment. It should be noted that economic instruments for stimulating innovation are quite well developed in theory and are actively used in practice, therefore, the relative comparative value of this indicator in the regional context cannot differ much [22].

Another critical factor is the comparative level of loyalty to innovation (A). Many states and regions make significant efforts to reduce the administrative burden on innovators, and help to level processes that historically inhibit innovation [23, 24].

The least attention is currently paid to the mechanisms of cooperation as objects of management in the development of the innovation environment. The formation of integration structures is usually limited only by the impact on the economic and administrative environment of innovation [25]. And cooperative ties as such remain poorly understood. We understand cooperation as a form of interaction of subjects in an innovative environment to obtain mutually beneficial effects by subjects, a qualitative increase in the level of economic activity or the implementation of a common project. Depending on the goals of interaction in the innovation environment, companies choose one or another degree of cooperation, including its extreme forms: market relations of the customer-supplier and integration. The high degree of cooperation and the speed of establishing connections can make it possible to get ahead in the promotion of technology and take a leading position in the technological field. Therefore, it is necessary to provide all kinds of support from the regional authorities precisely for building cooperative relationships while maintaining attention to other factors in the development of the innovation environment.

Cooperation management should be ensured by:

- comprehensive support for the transition from a rival to a partner relationship in an innovative environment by providing financial and other benefits;

- providing access to local markets only in cooperation;

- providing integrated access to the results of research;

- establishing rules for cooperation with risk dissipation;

- stimulating the development and implementation of cooperation strategies for participants in the innovation environment.

With increased attention to cooperation, leading companies will provide themselves with increased efficiency by optimizing costs, increasing added value, using the intellectual property of a partner company, etc. Supplying companies will acquire long-term partners on mutually beneficial conditions for stable growth.
In real conditions, the influence of factors restraining the growth rate of the level of development of the innovation 
On the other hand, the level of cooperation should not exceed a certain level at which entrepreneurial activity is reduced due to a stable long-term perspective.

Management of the level of innovation environment subjects' cooperation will allow to stimulate technological development and obtain economically valuable results from joint management at the level of groups of companies, industries or regions due to the concentration of innovative activity in the innovation environment.

\section{DISCUSSION}

An analysis of existing theories of technological development and economic cycles is carried out based on the works of N.D. Kondratyev [1], J. Schumpeter [2], as well as modern Russian economists S. Glazyev [5], Yu.V. Jacob [3] and others. We agree with the researchers regarding the provisions on the dynamic concept of the cycle, innovation as the driving force of technological development and overall economic growth at the macroeconomic level, the wave-like process of economic growth. Also, the time frame of technological cycles is based on the writings of these researchers and the classical model of changing technological waves. However, for the development of the theory, we have introduced the concept of a technological field to account for the unevenness of regional technological development, since it is not reflected in the considered works.

Issues of the development of the innovation environment are raised in the works of M. Castells (M. Castells, "The Information Age: Economics, Society and Culture", translated from English under the scientific editorship of O. I. Shkaratan, M.: HSE, 2000, p. 606), L. Gokhberg (L. Gokhberg et al., "Developing and using indicators of emerging and enabling technologies", Handbook of Innovation Indicators and Measurement, Elgar, Cheltenham / Northampton, 2013), Y.V. Tomilina [23], D.V. Kotov (D.V. Kotov, "Assessment of the innovative development of the national economy", [Actual issues of economics and management: materials of the International Scientific Conference (Moscow, April 2011). T. I.], M.: RIOR, pp. 29 - 33, 2011). We have laid the generation of synergy as a feature of the innovation environment as the basis for assessing the level of development of the innovation environment according to the findings in the above works. However, we have finalized the model of the innovative environment and have reflected the relationship with the level of technological development. We have also proposed to take the role and strength of cooperative interactions as a basic characteristic of the level of development of the innovative environment since this is not observed in previous studies in this area.

The theoretical foundations of the essence of the phenomenon of cooperation were considered by K. Marx (K. Marx, F. Engels, "Works", 2nd ed., M., 1955, p, 698), O. Williamson (O. Williamson, "The Economic Institutions of Capitalism", New York: Free Press.; O. Williamson, "Markets, Hierarchies, and the Modern Corporation: An Unfolding Perspective", in Journal of Economic Behavior and Organization, Vol. 17, pp. 335 - 352,1992.), J. F. Moore (J.F. Moore, "The Death of Competition. Book Review and
Commentary by Herb Rubenstein", President, Sustainable Business Group), Yu.V. Piskulov (Yu. V. Piskulov, "Conceptual features of modern intercompany production cooperation", Russian Foreign Economic Bulletin, No. 11, pp. 42- 59, 2014). The researchers have examined the types of cooperation and have proved the advantages of intercompany partnerships, which are recognized and taken into account in their studies. But the lack of practical instruments for managing cooperation has become the reason for the addition of scientific results in the field of the innovation environment.

Management as a purposeful change in the conditions of cooperation and competition, and methodological approaches to the implementation of these processes were studied in the works of F. Webster (F. Webster, "The Changing Role of Marketing in the Corporation", in Journal of Marketing, Vol. 56, pp. 1-17, 1992), K.Yu. Egiazarova (K. Yu. Egiazarova, "Actual directions of industrial cooperation between large and small businesses", Strategy and mechanisms for regulating industrial development, No. 3, 2011), O.V. Nikulina (O.V. Nikulina, A.A Kuznetsov, "International cooperation as a mechanism for the interaction of industrial enterprises in the field of innovation", National interests: priorities and security, No. 4 (337), 2016), S.G. Khomich (S.G. Khomich, 'Intercompany cooperation in innovation: the theoretical foundations of analysis", Bulletin of St. Petersburg University. Ser. 8. Management, No. 3, 2014), O.V. Popova (O.V. Popova, "Evaluation of the effectiveness of cooperation between small businesses", in Economic Sciences, No. 5 (66), pp. $156-160,2010)$ and many others. Our opinion coincides with the findings of scientists on the causes and risks of cooperation, as well as on the criteria for choosing a partner. But at the same time, the mechanism and practical recommendations for cooperation have not been developed. In this regard, we have developed the practical part of the management of cooperation in the innovative environment as an applied scientific result.

Thus, many aspects of the identified scientific problem were considered by scientists both in Russia and abroad. However, the theoretical justification of the relationship between the processes of origin, implementation, and termination of cooperative relations of market entities when changing technological structures from the position of managing these processes to increase economic efficiency, taking into account differences in innovative environments has not been carried out.

\section{CONCLUSION}

The scientific results obtained in the course of the study have made it possible to form a theoretical base of scientific principles in the field of technological development management, cooperation, innovative activity. These results also have let us build and justify the hypothesis based on the formed theoretical base. We have supplemented the terminology of the considered areas of knowledge with new concepts and have improved models from the point of view of cooperation management.

We have also formed the logic of the concentration of innovative activity of enterprises in those innovative 
[7] Mario Coccia, "Sources of technological innovation: Radical and incremental innovation problem-driven to support competitive advantage of firms", Technology Analysis and Strategic Management, 2017, 29:9, pp. 1048-1061.

environments that allow enterprises to receive the maximum economic benefits from the development of innovations. This new logic was correlated with the classical model of changing technological patterns.

The analysis of the factors contributing to the formation of the innovation environment has allowed us to construct a model of the innovation environment in conjunction with the level of technological development. The strength of the cooperative relationships of the enterprise was put as the basis for assessing the level of development of the innovation environment.

We have proposed a logical rationale and mathematical expression that reveal key areas for managing the accelerated development of the innovation environment. The role of cooperation in technological development was substantiated, and we have formulated proposals for managing the level of cooperation.

Additionally, we have conducted a comparison of scientific results with research in related fields of science of innovation management.

In planned further research to test the hypothesis and test the results, we will develop a mechanism and substantiate the management of cooperation by building a matrix for choosing the form of cooperation. We have also planned to form a set of practical recommendations on the use of various forms of cooperation for companies in the conditions of the innovative environment of a new technological structure.

\section{ACKNOWLEDGMENT}

The reported study was funded by RFBR, project number 19-310-90045.

\section{REFERENCES}

[1] N. D. Kondratyev, Yu.V. Yakovets, and L.I. Abalkin, "Big cycles of conjuncture and the theory of foresight", selected works, Moscow: Economics, p. 766, 2002.

[2] J. A. Schumpeter, "Ten Great Economists: From Marx to Keynes", translation from English by N. V. Avtonomova, I. M. Osadcha, N. A. Rozinsky; edited by V. S. Autonomies, Moscow.: Publ. Gaidar Institute, 2011, $400 \mathrm{p}$.

[3] Yu. V. Yakovets, "Global Economic Transformations of the 21st Century", Moscow: Publ. Economics, 2011, 381 p.

[4] I. A. Prokhorov, "The Beginning of the 7th Technological Order", BUSINESS Online [Electronic resource]. Available at: https://www.business-gazeta.ru/blog/352133.

[5] S. Yu. Glazyev, "A sprint to the future. Russia in new technological and world economic structures", Moscow.: Publ. Book's world, 2018, 768 p.

[6] Isabel Alvarez, Debora Di Caprio, and Francisco Javier SantosArteaga, "Technological assimilation and divergence in times of crisis", Technological and Economic Development of Economy, 2016, 22:2, pp. 254-273.
[8] H. Wang and S. M. N. Islam, "Construction of an open innovation network and its mechanism design for manufacturing enterprises: a resource-based perspective", Front. Bus. Res. China, 2017, 11, 3.

[9] E. R. Alekseeva, "Determination of the innovative environment and the factors of its formation", Proceedings of the XI Intern. scientific and practical. conf. "State and business. Modern problems of the economy" (April 24-26, 2019, St. Petersburg), North-West Institute of Management, RANEPA under the President of the Russian Federation, vol. 5, pp. 164-172.

[10] L. Faey and R. Randall, "MBA Course in Strategic Management", Translated from English. under the editorship of V. Osipova, M.: Alpina Business Books, pp. 596, 2004.

[11] K. Laursen and A. Salter, "Open for Innovation: The Role of Openness in Explaining Innovative Performance among UK Manufacturing Firms", Strategic Management Journal, 2006, vol. 27, no. 2, pp. 131150.

[12] D. Corsaro, C. Cantu, and A. Tunisini, "Actors' Heterogeneity in Innovation Networks", Industrial Marketing Management, 2012, vol. 41, pp. 780-789.

[13] L. Muhdi, "Open innovation and collaboration for innovations", Contemporary Accounting Research, 2011, 27 (2), pp. 345-345.

[14] P. Nakagaki, J. Aber, and T. Fetterhoff, "The challenges in implementing open innovation in a global innovation-driven corporation", Research-Technology Management, 2012, 55 (4), pp. 32 38.

[15] T. Turiera and S. Cros, "50 examples forbusiness collaboration", Magazines Infonomia, IF, 2013, no. 76, 51 p.

[16] Y. Nikolaidis, K. Fouskas, and E.G. Carayannis, "Assisting regional policy by rapidly comparing enterprise innovation between regions", J. Innov Entrep, 2013, 2, 16.

[17] M. Srholec, "Understanding the diversity of cooperation on innovation across countries: multilevel evidence from Europe, Economics of Innovation and New Technology", 2015, 24:1-2, pp. 159-182.

[18] P. Faria and T. Schmidt, "International cooperation on innovation: Firmlevel evidence from two European countries", Innovation, 2012, 14:3, pp. 303-323.

[19] P. Wassmann, D. Schiller,L. T. Stephan,"Spatial cooperation patterns and their impact on innovation outcomes: lessons from firms in a lowtechnology region”, European Planning Studies, 2016, 24:5, pp. 833864.

[20] Ya. V. Tomilina, "The Process of Forming an Organizational Innovation Environment", Basic Research, 2014, no. 6 (Part 2), pp. 335-339.

[21] M. Westerlund and R. Rajala, "Learning and Innovation in InterOrganizational Network Collaboration", Journal of Business and Industrial Marketing, 2010, vol. 25, no. 6, pp. 435-442.

[22] A. N. Alekseev, "Development of the innovation environment at the federal and regional levels", TDR, 2013, no. 6-2.

[23] X. M. Xie, S.X. Zeng, and C.M. Tam, "Overcoming barriers to innovation in SMEs in China: A perspective based cooperation network", Innovation, 2010, 12:3, pp. 298-310.

[24] R. Sternberg and O. Arndt, "The Firm or the Region: What Determines the Innovation Behavior of European Firms?", Economic Geography, 77:4, pp. 364-382, 2001.

[25] I.N. Platonova and others, "International economic relations in the era of globalization", MGIMO of the Ministry of Foreign Affairs of Russia, department, Department of International Economic Relations and Foreign Economic Affairs of the Ministry of Foreign Affairs of Russia, M., 2008, pp. 39-40. 